\title{
REMEDIATION OF SOIL CONTAMINATED WITH TOXIC ORGANIC COMPOUNDS USING MICROORGANISMS
}

\author{
${ }^{1 *}$ Ibrahim Khalil Adam, Abdullahi A. Imam ${ }^{2}$ and Muhammad Bello Yarima ${ }^{3}$ \\ 1. Department of Biochemistry, Federal University Dutse, Nigeria \\ 2. Department of Biochemistry, Bayero University, Kano-Nigeria \\ 3. Department of Microbiology and Biotechnology, Federal University Dutse, Nigeria \\ *Corresponding author: ibrahimkhalil_adam@yahoo.com
}

\begin{abstract}
Microorganisms, especially genetically modified microorganisms have continued to attract attention as a safer and environmentally friendly alternative in the bioremediation of contaminated environments such as soil and water bodies. Soil pollution by organic compounds such as pesticides, industrial and agricultural solvents, dyes, pigments, additives etc. is on the increase worldwide as a result of industrialization and agricultural modernization. Toxicity from these and other related pollutants have constituted a major challenge to humans as well as the environment. Therefore, it is important to apply effective remediation measures to reduce the levels of these toxicants so as to minimize the risk of bioaccumulation in agricultural food products. Bioremediation using biological materials viz; whole cells, cell extracts, isolated enzymes etc. is one of the most effective and environmentally friendly approaches currently in use. This paper therefore, reviews the current microbial remediation strategies of soil contaminated with various organic pollutants.
\end{abstract}

Keywords: Bioremediation, Microorganisms, Pollutants, Soil, Organic

\section{INTRODUCTION}

Industrialisation has led to the proliferation and utilisation of synthetic chemicals as organic solvents, fuel additives, pesticides, dyes and pigments, their consequent entry into the environment and potential toxicity. Life is believed to be affected by the quality of the environment (Mitchell, 1992; Skipper and Turco, 1995; Sikdar and Irvine, 1998; Vidali, 2001). Exposures to these compounds have both acute and cumulative effects on human health (Alexander,1994). Huge contamination has been reported in USA; an average adult ingests approximately $0.02 \mu \mathrm{g}$ of pesticides such ad DDT, toxaphene, dieldrin per body weight (Mitchell, 1992; Skipper and Turco, 1995). In the United Kingdom, it was estimated that there may be 300,000 hectares of land contaminated with toxic compounds from previous industrial activities (Lynch and Moffat, 2005). Consequently, for sustainability the need to clean up contaminated soil is obvious, and commonly done using conventional methods such as land filling, incineration, chemical treatment, physical and hydraulic barriers and these proved inefficient (Skipper and Turco, 1995).

Landfilling has lots of limitations due environmental regulations, costs, inefficient and risks of producing green house gases and leachate that may lead to groundwater pollution. It cost up to $\$ 1$ million per hectare to construct and requires costly maintenance. The number of landfill decreased from 18500 in 1979 to 1762 in 2002 in the US. Incineration is faced with high cost, and disposal of ashes or residues thus increasing pollution. Chemical method is not cost effective and often lead to production of harmful compounds (Skipper and Turco, 1995; Pepper et al., 2006). It cost between $\$ 150-\$ 250$ per yard to clean up a site by landfilling, costs as high as $\$ 250-\$ 800$ for incineration while as low as $\$ 40-\$ 100$ is required for bio-treatment of same site (Crawford and Crawford, 1996).

Bioremediation refers to removal, transformation or degradation of pollutants using microbes, cell extracts (enzymes), or plants. It has emerged as a cheaper, effective, sustainable and environmentally safe method of waste management with high public acceptance. Bioremediation also achieves a greater level of degradation of pollutants with less impact on environmental flora and fauna (Skipper and Turco, 1995; Hickey and Smith, 1996; Vidali, 2001; Ang et al., 2005). This write up will focus on microbial remediation of soil contaminated with toxic organic compounds.

Organic Pollutants

Xenobiotics are synthetic compounds that are not found in nature which include pesticides, polychlorinated biphenyls (PCBs), dyes, chlorinated solvents and munitions (Madigan et al., 2009). Organic contaminants include Chlorinated solvents like trichloroethylene and perchloroethylene; PCBs include 4-Chlorobiphenyl and 4,4-Dichlorobiphenyl; Chlorinated phenol like pentachlorophenol. Aliphatic and polyaromatic hydrocarbons (PAHs) including alkanes, naphthalene, anthracene, benz(a)pyrene; benzene, toluene, ethylbenzene, xylene referred to as "BTEX"; pesticides like atrazine, carbofuran, and glycophosate (Ni et al, 2014; Vidali, 2001). Others include pharmaceuticals, food additives, cosmetics, drugs and dyes. Some of these can be carcinogenic(Mitchell, 1992; Wilson and Jones, 1992; Alexander, 1994; Pepper et al., 2006). These chemicals are produced in industrial processes such as gasification / liquefaction of fuels, catalytic cracking, landfill / waste dumps, open burning, incineration, fuel / oil production, storage and transport, coke production timber treatment and agriculture. 
Microbes have the capacity to degrade many of these compounds to a large extent (Wilson and Jones, 1992; Vidali, 2001). The rate of degradation and toxicity determines the potential hazards of pollutants in the environment, aliphatic and aromatic hydrocarbons are biodegradable but slow in limited water solubility and branching and halogenations also slow the process. Polycyclic aromatic hydrocarbons are highly hydrophobic carcinogens with slow biodegradation (Pepper et al., 2006). The degradation of these compounds is affected by aerobic and anaerobic conditions; petroleum hydrocarbons and pesticides degrade more readily in aerobic condition as compared to anaerobic condition and thus tend to accumulate in the environment (Mitchell, 1992; Alexander, 1994; Pepper et al., 2006). Aerobic degradation of pesticides and hydrocarbons like alkanes and PAHs by Pseudomonas, Alcaligenes, Rhodococcus, and Mycobacterium has been reported. Anaerobic bacteria are of interest for bioremediation of PCBs and TCE (Vidali, 2001). Persistence of pollutants results in bioaccumulation and potential toxicity to human health and environment. Plant insecticides such as pyrethroids; organochlorine such as DDT; fumigants persist in the environment and have some degree of toxicity to life (Mitchell, 1992).

\section{Reasons for Persistence}

Persistent organic pollutants (POPs) are chemicals that are highly distributed and toxic due to their accumulation in fatty tissues of living organisms. They include PCBs, DDT, dieldrin, furans, hexachlorobenzene (Pepper et al., 2006; Cheng et al., 2016). Persistence may result due to the inability of microorganisms to metabolise the xenobiotics because of lack of enzymes system required for biodegradation. The complex nature of pollutants and selectivity of microorganisms for easily degradable carbon sources affect biodegradation, they tend to grow slowly if a foreign toxic compound is the carbon source thus slow degradation (Alexander, 1994). Many compounds yield toxic and recalcitrant intermediates that inhibit microbial activity. Petroleum hydrocarbons generate hydroxylated intermediates example 2,3dihydroxynaphthalene, an intermediate in naphthalene breakdown is more toxic to marine bacteria than naphthalene (Mitchell, 1992; Paul et al., 2005).

Organic compounds may be partially or wholly resistant to mineralisation by the addition of physiologically uncommon substituent (xenophore) like $\mathrm{Cl}, \mathrm{Br}, \mathrm{CN}$ which are foreign to microbes (Alexander, 1994). Unfavourable conditions decrease microbial activities hence affecting biodegradation rates subsequently leading to persistence (Mitchell, 1992). The availability of nutrients is also a limiting factor in microbial remediation; microbes use organic nutrient sources and release the bound residues into soil to undergo biodegradation. Genetic and physiological diversity of microbes affects the rate of degradation or transformation by different microbes (Skipper and Turco, 1995).

Bioavailability of contaminants to microbes is another affecting the persistence of organic pollutants in the soil. Bioavailability is affected by various factors among which are soil structure and texture (Skipper and Turco, 1995; Crawford and Crawford, 1996). Pollutants such as PAHs and chlorinated pesticides may not be available for microbial activity and thus persist in the environment due to their hydrophobic nature (Paul et al., 2005).

\section{Microbial transformation pathway}

Biotransformation or biodegradation of pollutants occurs in both aerobic and anaerobic conditions. Microbes transform organic compounds to a form that can be incorporated into cells and synthesis of cell molecules (Sikdar and Irvine, 1998; Pepper et al., 2006). Biotransformation is facilitated by enzymes during normal metabolism of the organism leading to degradation of pollutants(Mitchell, 1992). Cometabolism is often used by microbes to degrade organic pollutants like chlorinated solvents using a primary substrate (Crawford and Crawford, 1996). Chain length and solubility of compounds like aliphatic hydrocarbons affect degradation, polycyclic aromatics and organic pesticides are less soluble, toxic and mobile thus are slowly transformed or biodegraded (Mitchell, 1992). Bioremediation of azo dyes in textile effluents using Aspergillus oryzae has been reported (Corso and Ammeida, 2008).

The genes that encode the biodegradation enzymes of PAHs have been identified, isolated and characterised and this has enable engineering of novel microbes such as Pseudoalteromonas haloplanktis TAC125 for improved remediation of aromatic compounds (Ang et al., 2005; Papa et al., 2009). 2,4,6-trinitrotoluene (TNT) a toxic, mutagenic and persistent explosive soil and ground water pollutant can be transformed under aerobic and anaerobic conditions by nitro-group removal (Lewis et al., 1997). TNT can also be transformed by Veinella alkalescens and Clostridium pasteunanum as well as C. biofermentum, a microbe isolated from a long term bioreactor fed with munitions compounds (Lewis et al., 1997). Furthermore, Alkaloids are transformed by Pseudomonas putida, lysergamide is hydrolysed by an amidase from Rhodococcus equi. Arthrobacter nicotinovorans grows on nicotine as its sole carbon source and degrade it; genes involved in nicotine degradation have been identified on plasmid PAO1 (Rathbone and Bruce, 2002).

PCBs are biodegraded to TCA intermediates and (chloro)benzoate, the reaction is catalysed by biphenyl dioxygenase (Ang et al., 2005). Laccases and cytochrome P450 monooxygenase degrade PAHs, laccases genes are reported in Myceliopthora thermophia. Pseudomonas putida degrades PAHs while Burkholdena capacia and Pseudomonas pseudoalcalgenes transform PCBs using the biphenyl dioxygenase enzyme (Ang et al., 2005). Bacteria degrade organophosphates; Pseudomonas diminuts transform organophosphates by hydrolysis using the phosphoesterase (organophosphorous hydrolase). Reductive dechlorination of chroninated compounds; Bukholderia desulfomonile reduce chlorobenzoate to benzoate (Ang et al., 2005). Pseudomonas species oxidize oil to $\mathrm{CO}_{2}$ this activity is promoted by nutrient supplementation. Up to $80 \%$ of non volatile compounds can be oxidized within a year of spill (Madigan et al., 2009). 


\section{Bioremediation Strategies}

In situ and ex situ are methods used in bioremediation; in situ refers to in-place treatment of a contaminated soil it is applied for fuels and is highly dependent on the structure of the contaminants and is of lower cost. Ex situ refers to aboveground treatment of soil or water that is removed from a contaminated site (Vidali, 2001; Pepper et al., 2006).

Land farming

Tilling and irrigation create favourable environment for microbial activity and increase bioavailability of contaminants, the soil may require nutrient and oxygen supplementation to enhance microbial activity. The method is inexpensive and effective but must be performed with caution to avoid creating contamination problem (Crawford and Crawford, 1996). Landfarming is used in the treatment of aquifer contaminated by trichloroethylene and dichloroethylene (Wilson and Jones, 1992).

\section{Composting}

This involves piling the soil and mixing it with nonhazardous organic agents such as manure or agricultural wastes, wood chips. It enhances establishment of microbial population and increased temperature (Vidali, 2001). The pile is aerated and the moisture content, $\mathrm{pH}$ and nutrient contents are controlled to enhance microbial activity (Wilson and Jones, 1992).

\section{Above ground Bioreactors}

Contaminated soil is excavated and put into a reaction vessel where it is treated, slurred with water and bioremediation conditions are optimised. It can be done both in aerobic and anaerobic conditions; inoculums may be introduced to ensure complete degradation of organic compounds. Successful remediation of pentachlorophenol, organochlorine, organophosphates has been achieved using this method (Skipper and Turco, 1995).

\section{Bioventing}

Air is introduced by a blower or vacuum system, increasing the amount of oxygen enhances biodegradation. Limitation is that difficulty arises in soils that are impermeable and restrict movement of air, is used for pollutants like petroleum hydrocarbons where the contamination is deep (Crawford and Crawford, 1996; Vidali, 20001; Pepper et al., 2006).

\section{Bioaugmentation}

It refers to the introduction of the required microorganisms to the contaminated soil, can be injected into the subsurface. The process is difficult; some introduced microbes may not survive since they cannot often establish a niche due to competition and difficulty in delivering them to the target site (Pepper et al., 2006).

\section{Monitored natural attenuation}

This is the natural transformation but requires strict monitoring to be sure it works. Attenuation may be through biodegradation, hydrolysis, sorption and dilution of contaminants. It has being successful for soils contaminated by petroleum hydrocarbons such as gasoline. The magnitude and rate of attenuation have to be determined (Pepper et al., 2006).

\section{Biosparging (Air Sparging)}

This involves forcing air through a point or points below the water table which enhances aerobic biodegradation, the microbes use the organic chemicals as nutrient sources effective in removing volatile organic compounds from vadose and saturated zones (Benner et al., 2000; Vidali, 2001).

\section{Biopiles}

Biopiles are interface of composting and land farming; cells are designed as aerated piles, used for the remediation of surfaces polluted by petroleum hydrocarbons. Provide a conductive environment for aerobic and anaerobic microbes (Vidali, 2001).

\section{Field Cases}

In March 1989, a crude oil spill of 41 million litres of crude oil occurred in Alaska contaminating about 2000 $\mathrm{Km}$ of rocky intertidal shoreline. Bioremediation was used to treat the contaminants; on-site treatment and fertilizer application was used, $50000 \mathrm{Kg}$ of nitrogen and $5000 \mathrm{Kg}$ of phosphorous were applied. This enhanced biodegradation of the crude, thus demonstrated the use of bioremediation in the cleanup of contaminated sites (Bragg et al., 1994).

In Southeast Texas, methyl tert-butyl ether (MBTE) storage tank leaked and led to groundwater pollution in its vicinity; MBTE concentrations ranging from $13,000 \mathrm{mg} / \mathrm{l}$ to $42,00 \mathrm{mg} / \mathrm{l}$ was measured. Excess nitrogen and phosphorous were added to the bioreactor, microbes present were able to reduce MBTE concentrations in bioreactor from $2,400 \mathrm{mg} / \mathrm{l}$ to very low value of $1.6 \mathrm{mg} / \mathrm{l}$ at an average removal rate of $96.2 \%$ (Stocking et al., 2000).

Bioaugmentation was used in China for remediation of oily sludge contaminated soil containing large amount of heavy oil; reduction of total hydrocarbon by $45-$ $53 \%$ was observed within 56 days, reduced toxicity evident by growth of Tall Fescue tree (Festuca arundinance) which further reduced the hydrocarbon content by 5-7\% (Ouyang et al., 2005).

\section{Limitations of Bioremediation}

Like any other technology, the success of bioremediation is faced with lots of challenges; some contaminants such as chlorinated and highly aromatic hydrocarbons resist biodegradation. They are degraded at slow rate or not at all (Skipper and Turco, 1995; Vidali, 2001).

Organic compounds produce toxic intermediates that inhibit microbial growth. Microbes preferentially metabolize more readily available carbon sources, making them to degrade xenobiotics may be difficult. The contaminant may be completely or partially inaccessible to the microbes (Mitchell, 1992; Skipper and Turco, 1995). Organic compounds are often hydrophobic which make them unavailable to microbes. Another limitation is insufficient knowledge of the degradation pathways for several recalcitrant compounds (Paul et al., 2005). The presence of correct microbial population capable of degrading contaminants and environmental conditions are limiting factors in bioremediation. Acceptable performance criteria due to regulations regarding the success of bioremediation are challenging. Bioremediation is slow takes longer than other treatment methods (Vidali, 2001). 


\section{Solutions}

Microbes capable of degrading recalcitrant compounds are being made using batch enrichment, chemostat selection and genetic engineering. The performance of organisms can only be ensured if it has a selective advantage for growth on the substrate and competitive advantage over the wild species in contaminated soil (Skipper and Turco, 1995; Papa et al., 2009). An engineered strain P. haloplanktis has the ability to grow on aromatic compounds and degrade them (Papa et al., 2009). The use of isolated enzymes rather than an entire organism has also been suggested (Skipper and Turco, 1995). Environmental conditions such as $\mathrm{pH}$ and oxygen can be optimised by the use of hydrogen peroxide and magnesium peroxide which produce oxygen at levels higher than can be achieved by aeration. The $\mathrm{pH}$, carbon nitrogen and phosphorous can be maintained by the addition of lime, nutrients and fertilizers. Moisture content and soil texture are improved by sorption and homogenisation (Wilson and Jones, 1992; Pepper et al., 2006). Tilling and air sparging are used to increase aeration, plastic covering can be used in late spring, summer and autumn to enhance warming (Vidali, 2001). Soil structure and permeability affect air, water and nutrients availability and are amended by the application of gypsum or organic matter (Vidali, 2001). The C:N:P is maintained at 100:10:1 ratio (Vidali, 2001; Pepper et al., 2006).

Biosurfactants detergent-like chemicals that facilitate contact between microbes and hydrophobic compounds increase bioavailability of compounds thus enhance microbial degradation. These are non-toxic,

\section{REFERENCES}

Alexander, M. (1994) Biodegradation and bioremediation. San Diego: Academic Press.

Ang, E.L., Zhao, H., and Obbard, J.P. (2005). Recent advances in the bioremediation of persistentorganic pollutants via biomolecular engineering. Enzyme and Microbial Technology 37: 487-496.

Benner, M.L., Stanford, S.M., Lee, L.S., and Mohtar, R.H. (2000) Field and numerical analysis of in-situ air sparging; a case study. Journal of Hazardous Materials 72: 217-236.

Bragg, J.R., Prince, R.C., Harner, E.J., and Atlas, R.M. (1994) Effectiveness of bioremediation for the Exxon Valdez oil spill. Nature 368: 413418.

Cheng M., Zeng G., Huang D., Lai C., Xu P., Zhang C., and Liu Y. (2016) Hydroxyl radicals based advanced oxidation processes (AOPs) for remediation of soils contaminated with organic compounds: A review. Chemical Engineering Journa/ 284: 582-598

Corso, R.C., and Ammeida, D. (2008) Bioremediation of dyes effluent by Aspergillus oryzae. Microbial Ecology 57: 384-390.

Crawford, R.L., and Crawford, D.L. (1996) Bioremediation: principles and applications. Cambridge ; New York: Cambridge University Press. non-hazardous, biodegradable and cheap compounds. Bioremediation of chlorinated pesticides, n-alkanes, polycyclic aromatic hydrocarbons has been achieved this way (Paul et al., 2005). Alcanivorax borkumensis grows only on surfactants, break up the oil and solubilise it (Madigan et al., 2009). The use of genetic engineering to alter the substrate specificity of biodegradation enzymes through site-directed mutagenesis and gene shuffling is promising as in biphenyl dioxygenase specificity (Ang et al., 2005; Paul et al., 2005; Papa et al., 2009).

Coordination and integration of research from experts in microbiology, biochemistry, ecology, soil science, physiology, environmental chemistry, hydrogeology and engineering will improve bioremediation (Skipper and Turco, 1995; Vidali, 2001).

\section{Conclusion}

Environmental pollution has increased over the years due to man's activities. Awareness has increased on toxicity of recalcitrant organic contaminants; polychlorinated biphenyls, polycyclic aromatic acids and pesticides. The need for safe and efficient technology to clean up the environment led to the acceptance of bioremediation as alternative to traditional methods (Ang et al., 2005; Paul et al., 2005). Bioremediation has been used to successfully cleanup sites in various places. However the success of the technology is faced with limitations such as environmental conditions, persistence of pollutants, bioavailability of pollutants and viability of microbes. Genetic engineering and some other strategies are being explored to address these limitations (Ang et al., 2005; Paul et al., 2005)

Hickey, R.F., and Smith, G.L. (1996) Biotechnology in industrial waste treatment and bioremediation. Boca Raton: Crc.

Lewis, T., Ederer, M., Crawford, R., and Crawford, D. (1997) Microbial transformation of 2,4,6trinitrotoluene. Journal of Industrial Microbiology \& Biotechnology 18: 89-96.

Lynch, J.M., and Moffat, A.J. (2005) Bioremediationprospects for the future application of innovative applied biological research. Annals of Applied Biology 146: 217-221.

Madigan, M.T., Madigan, M.T., and Brock, T.D. (2009) Brock biology of microorganisms. SanFrancisco, CA: Pearson/Benjamin Cummings.

Ni H., Zhou W., and Zhu L. (2014) Enhancing plantmicrobe associated bioremediation of phenanthrene and pyrene contaminated soil by SDBS-Tween 80 mixed surfactants. Journal of Environmental Sciences 26: 10711079

Mitchell, R. (1992) Environmental microbiology. New York: Wiley-Liss.Ouyang, W., Liu, $H_{\text {., }}$ Murygina, V., Yu, Y., Xiu, Z., and Kalyuzhnyi, S. (2005) Comparison of bio-augmentation and composting for remediation of oily sludge: A field-scale study in China. Process Biochemistry 40: 3763-3768.

Papa, R., Parrilli, E., and Sannia, G. (2009) Engineered marine Antarctic bacterium 
Bajopas Volume 10 Number 1 June, 2017

Pseudoalteromonas haloplanktis TAC125: a promising micro-organism for the bioremediation of aromatic compounds. Journal of Applied Microbiology 106: 49-56.

Paul, D., Pandey, G., Pandey, J., and Jain, R.K. (2005) Accessing microbial diversity for bioremediation and environmental restoration. TRENDS in biotechnology 23: 135-142.

Pepper, I.L., Gerba, C.P., and Brusseau, M.L. (2006) Environmental \& pollution science. Amsterdam: Academic Press.

Rathbone, D.A., and Bruce, N.C. (2002) Microbial transformation of alkaloids. Current Opinion In Microbiology 5: 274-281.
Sikdar, S.K., and Irvine, R.L. (1998) Bioremediation: principles and practice. Lancaster, Pa.: Technomic Pub. Co.

Skipper, H.D., and Turco, R.F. (1995) Bioremediation: science and applications. Madison, Wis.: Soil Science Society of America.

Stocking, A.J., Deeb, R.A., Flores, A.E., Stringfellow, W., Talley, J., Brownell, R., and Kavanaugh, M.C. (2000) Bioremediation of MTBE: a review from a practical perspective. Biodegradation 11: 187-201.

Vidali, M. (2001) Bioremediation. An overview. Pure Appl. Chem 73: 1163-1172.

Wilson, S.C., and Jones, K.C. (1992) Bioremediation of soil contaminated with Polynuclear aromatic hydrocarbons (PAHs): A Review. Environmental Pollution 81: 229-249. 